\title{
ESBOÇO DE ENSAIO PARA DESCONSTRUÇÃO DO DISCURSO PENAL NA SOCIEDADE DO ESPETÁCULO, OU... SURPREENDENDO O PÚBLICO EM QUINTAIS PRIVADOS
}

Ricardo Aronne*

RESUMO - Uma das mais difusas dicotomias ainda presentes no discurso jurídico contemporâneo é a noção de Público e Privado. Essencial ao Liberalismo Clássico, essa dicotomia, revela agora sua crise. Esse artigo, em respeito às suas raízes existencialistas, posta suas lentes desconstrutoras nessas noções, para encontrar por trás delas o homem real (demasiadamente humano).

PALAVRAS-CHAVE - Público. Privado. Discurso. Existencialismo. Pós-Modernidade. Humanismo. Arqueologia.
ABSTRACT - One of the most difuses dicotomies in contemporary juridic discourse, is the notion of Public and Private. Essencial for the Classical Liberalism, this dicotomy, now, reveal your crisis. This article, respecting his existencialist's roots, plain your deconstructive lenses on that notions to search a real man (excessively human), behind that.

KEY WORDS - Public. Private. Discourse. Existencialism. Post-Modernity. Humanism. Arqueology.

\section{Um Foyer ao Discurso}

Há civilistas que sequer ousariam reconhecer-se propriamente privatistas. Por que privar-se do mundo, como espaço capaz de reconhecerse como fruto de um discurso que o conforma enquanto realidade líquida, porquanto nos conforma no autoengano da cultura da segurança e da "metafisicidade" de uma salvaçãoprome(n)tida? Seu desengano existencialista faz risíveis as fronteiras cartesianas das especializações.

* Doutor em Direito pela UFPR, Professor do PPG-Direito da PUCRS.

\begin{tabular}{|l|l|l|l|l} 
VERITAS & Porto Alegre & v. 53 & n. 2 & abr./jun. 2008
\end{tabular}


Eu os vejo no espelho, ao fazer a barba. Eles me ajudam a contar os dias de um lacaniano tempo líquido, há muito distante de quaisquer ponteiros. Um tempo humano. Da humanidade... Sem pertença e credor de pertencimento. Que somente passa em volta das fogueiras. Quando voltamos ao instinto primacial de sobreviver.Transcender-nos. Na tradição. Em nossas histórias. Contando o passar dos tempos. Sobrevivendo por nossas histórias. Falar sobre o Direito, para além da razão, muito mais que para além da raiz da razão, haverá de importar em contar uma boa história. Capaz de desconstruir qualquer outra história.Mas não seria por ousadia que me atreveria a olhar por cercas vizinhas. É pelo maior dos sentimentos que a amizade constrói, que o discurso da razão aderna, desvestido de culpas, para ganhar novos passaportes. É pelo afeto, que transpassa os umbrais da Academia, que cursou esse texto; para homenagear fraternos e paradigmáticos amigos que, mais ousados que eu, desafiam-me incansavelmente com o tema fustigado: Ricardo Timm de Souza, Salo de Carvalho, Aury Lopes Júnior, Ney Fayet Jr., Jacinto de Miranda Coutinho e Alexandre Wunderlich.

Se os temas tradicionalmente afeitos ao Direito Penal e à Criminologia nunca foram alvo de meu discurso, o mesmo não se diga daqueles que o motivaram. Meus amigos sempre foram a melhor interlocução de minhas idéias, cuja produção científica já remonta ao antigo milênio, na travessia democrática que vem reconstruindo o Brasil. Os amigos sempre serão o melhor motivo para que contemos uma boa história.

Assim, essa história sem ponto final, nascida do conforto privado... é dedicada a eles, que não cansam de se enredar por seus enredos e fazê-la pública.

\section{Uma crítica em rascunho}

Ensaiar um esboço ou esboçar um ensaio no encalço das raízes legitimadoras da Sociedade Punitiva que vive nas entranhas de uma Sociedade do Espetáculo, consumidora e produtora do crime e da pena, de modo a nunca conceber sua possível transcendência em outro paradigma, persegue questionar às raízes dessa mesma pena; eleita meio diante de fins axiologicamente difusos. Esse interdito permite uma arqueologia de outra eleição. Documentando a influência paradigmática, em verdadeira museologia das escolhas. De um sistema de verdades, históricogeograficamente comprometidas. Para com isso, no conjunto lógico, regido pelo princípio formal da não-contradição (no hipertrofiado sentido dado pela Escola de Viena e por David Hilbert em especial), aferir da legitimidade daquilo já circunscrito como ilícito; o que torna-lhe um ilícito penal. Crime, portanto. Paradoxalmente ignorante de seu sentido antropológico; um crime dogmaticamente vestido de lamentável utilitarismo econômico e político. Dilapidado do humanismo que o possa ter originariamente concebido ou mesmo constituído. Mais que forjado na luta de classes, foi parte da própria forja 
disciplinar dessa tensão socialmente fronteiriça. Do ter... em detrimento do ser. Crime, pois, assim edificado por um conjunto de regras supostamente neutro, asséptico de quaisquer valores morais (iluministicamente remetidos para o terreno da irracionalidade gótico-kelseneana); corporificados em um sistema fechado em austero templo disciplinar erigido sobre um estatuto de verdades metafísicas. O Código Penal... Um Código fruto de um Direito, por excelência, Burguês. Com cor, religião, sexo e status econômico-social. Não raro, com endereço certo. Axiológico por natureza, desde a eleição desse conjunto de bestas que a modernidade, ainda moribunda nas fronteiras do pós-guerra, tentava domesticar e que compõem cada indivíduo em sua particular condição. Valores. Eleitos por discursos que constituem verdades circunstanciais. Existenciais. Mesmo na supressão daquela liberdade que nos faz humanos. Até para dela abrirmos mão... desumanizando-nos.

$\mathrm{Na}$ raiz de cada discurso repousa uma eleição de valores. Na máscara dialética, disruptora da lógica natural do discurso não-sofista (onde as respostas se afiguram prontas antes das perguntas terem sido formuladas), potencializado pelo pensamento dicotômico (redutor e simplista, não obstante a presença entre espiritualistas e empiristas), esconde-se um inversão. As questões resultam postas na chegada do discurso em sua razão final. Porém, aí, já abrimos mão da liberdade existencial, hermenêutica, de compreender. Pois viver é interpretar viver.

Já nos deixaríamos manipular ao não indagar da intencionalidade da representação do fenômeno. Do porquê houve o convite para estar ali; questão fundamental para estar ali. Ser. Ou não... Nadificar... Nada... ficar. Nadificando. À tudo. À todos. À si. "Imanescer". "Destrancender". Não-ser. "Desser"... Evanescer. Envenenando à tudo e à todos. Esse discurso cartesiano tem contraponto em Pascal, com bem exploradas conseqüências em Edgar Morin. Oswald de Andrade, tantos anos atrás, em seu manifesto antropofágico, também fazia perceber isso; não obstante algum totalitarismo hegeliano sondar ao longe. É necessário desconstruir o discurso para descobrir a razão da eleição "do" discurso e não "pelo" discurso. Mais importante do que "onde chegou" é perguntar-se a razão de "onde partiu" e do "porquê foi proferido" o discurso.

Daí é possível uma genealogia do discurso em concreto, respeitada a não-linearidade daquele que o profere e o desvio hermenêutico possível daquele que o interpreta; previsível no princípio postal já descrito pela perspicácia de Derrida. Demarcada a incerteza de uma certa territorialidade epistemológica que se põe a ranger, quando alguma arqueologia dos saberes antropologicamente existencializada, transita pelos modernos cenários impressos no palco jurídico, deve-se prosseguir para além da desconstrução. Havemos de exumar as premissas, recolocando-as desnudas nas avenidas da complexidade pós-moderna, verificando o que sobra à colher do instrumental tradicional, após o necessário atrito com a (talvez não menos 
simbólica) realidade social perdida na "pós-tradicionalidade líquida". Circunstancie-se desde logo que esse texto toma para si o Direito como platô qualificado de análise enquanto crítica. É, pois, ainda que trajado de transdisciplinaridade, com as vestes talares desse Direito posto em transe, que estamos tratando; mesmo quando as branas que vibrarem pelo discurso, orquestrem a música dos muitos sistemas no seu ressoar nas respectivas esferas.

\section{Um apartheid sem cercas}

Os Códigos não nasceram com ou para as penas. "Apenas" se apropriaram delas. Os Códigos sequer nasceram olhando para interesses de ordem pública e sim, para esfera privada, após a fissura econômica do Estado nesses dois continentes, até então difusos e "pangeográficos", corporificados nos revolucionários direitos fundamentais de primeira dimensão.

Esses, na condição de amuleto contra o Leviatã, incapacitavam o Estado de retomar as liberdades do ancien régime. O mal necessário para que o homem hobbesiano não impusesse pela força, sua vontade diante do fraco e vulnerável. O Estado de Locke... Estado-Mínimo, Polícia, Gendarme. Revolucionariamente voltado para atender ao novo sujeito edificado pela modernidade. O indivíduo. O cidadão. Mas... qual cidadão?

Novamente importa desconstruir para perceber o fundamento da tutela em construção, pelo Direito Moderno, na Revolução que destroçou o Estado Absolutista e os resquícios feudais no Velho Mundo, o qual ainda no Século XIX estava a biografar a novela do Novo Mundo, em um arremedo de globalização disforme. O tempo andava sobre lerdas pernas, então. Distintas das rodas e turbinas que hoje lhe impulsionam. A Revolução Francesa fez, de muitos, sujeitos. Da larga maioria, sujeitados.

A razão se colhe nos fundamentos que o Iluminismo coou da Renascença. Nela, o Homem que emerge da Reforma (tanto de Calvino como de Lutero), lendo a Bíblia na própria língua, embalado nos braços de Guttemberg, descobria uma outra noção de igualdade, naquele Jusnaturalismo de matizes racionalistas que se impunha sobre o outrora místico, que já se apropriara do espaço de crença anteriormente de raízes cosmogônicas no politeísmo pagão.

Para o desconforto do Rei, os vassalos descobrem serem todos iguais diante do Deus que lhes atribuíra vida. Vida essa que nenhum outro homem poderia tirar. Mesmo São Tomás, fornecendo amplo contra-ponto às Cidades de Sto. Agostinho, afirmará então que diante do tirano, cabe seja ele morto! O despotismo olha com desespero os grãos escorrerem pela ampulheta que lhe mede o futuro... A Aristocracia decadente e em profunda atrofia, perde sua legitimidade em padrões cada vez mais nítidos. Afasta-se da Natureza. De sua natureza, povo e legitimidade. Agoniza... À Burguesia cabe apenas "iluminar os fatos" para que tudo venha às claras. Razão... Crucial será a percepção de que o paraíso destinado ao Homem enquanto 
morada, se reveste da condição de um direito natural à terra... à propriedade enquanto pertença. Futura medida da dignidade, na secura de discursos tão heterogêneos como os de Hegel ou Robespierre. Novos discursos... Novas vozes... Novos Senhores. A radicalidade da perspectiva Iluminista precipitará o Jusracionalismo como fundamento de um Direito posto nas bases do ideal de Ciência nascente. Mas isso é um processo. Apenas em início. Com Descartes arrancando o espírito da carne. Criando o Homem Dual, profícuo em dicotomizar para compreender. Dividir... Racionalizar... A razão será o único freio desse Homem profundamente livre. Modernamente livre. Com Benjamin Constant somos lembrados ser a liberdade dos "modernos" distinta dos "antigos". A vida pós-moderna nos insufla a um repensar profundo desses ideais antropofágicos. Esse Homem moderno, cujo estatuto de liberdades civis edificadas pelos direitos fundamentais nascentes (então direitos políticos) é solipsista por concepção. Fulcrado em seus direitos de exclusão, moduláveis tão somente por sua liberdade. Por sua expressão de vontade. Pelo contrato.

É desse contrato, ápice da expressão moderna da vontade (dit contratuél,c'est dit just, ou ainda, o contrato faz lei entre às partes), ápice da expressão da órbita do Privado, que nasce o Estado Moderno. Já em Rousseau, mas corporificado em Locke, do Contrato Social.

Esse Estado Gendarme, tem um compromisso por excelência: deixar tudo como está. Garantir o status quo. Agora, o cidadão, despojado da condição vassalar que lhe agrilhoava qual servo, é o Senhor. A saúde da nação será garantida pela Lei do Mercado, oferta e procura assegurada pela condição negativa do Estado, conforme a fórmula revelada por Adam Smith. Lex Mercatoria.

Mas, como isso é feito? Qual conjunção de capitais disciplinares seria capaz de explicar esses compromissos, instrumentalização, ação e resultados ? Novamente persegue-se uma desconstrução compreensiva da ciência moderna, que busca retirar as teorias e métodos que estruturou, de sua história e concreticidade que lhes atribuía e ainda atribui sentido. Portanto, existência; na carência de essência.

\section{Um Estado mínimo para o Homo sacer}

Após a lobotomia do Estado, por um conjunto de precisas incisões feitas pelo liberalismo, o Leviatã fora transformado em um risível aleijão. Um Quasímodo pronto a esconder-se nas torres de Notredame e ser confinado ao invisível; à escuridão da noite, esgueirando-se pelos telhados e espreitando as janelas, sem possibilidade de acolhida em qualquer lareira.

Um Público identificado como espaço de ninguém, na percepção de sua nêmese (qual o normando Ricardo e o sarraceno Saladin) no múltiplo Privado como espaço de alguém e cuja falta de convívio comum importava em seu próprio discurso de afirmação. Exclusão. O Estado Moderno nasce para a propriedade (Locke) e pelo contrato (Rousseau), fundado no conflito (Hobbes) 
para conter um abstrato (não obstante individual) ser livre e racional (Kant). Seu fundamento policial somente se justifica enquanto tutela da pertença individual do cidadão (eterno credor do Estado patrimonial burguês). Garantidor do status quo identificado com a propriedade privada e tendo, novamente, o contrato como partícipe, o instrumento de circulação dessa riqueza ora individual.

É, pois, nos paradoxos, que a "razão moderna" se explica em fundamento último. Irracionalizável, portanto. Irredutível. Irremediavelmente complexa. Impassível de simplificação. $\mathrm{Na}$ quebra de seu simulacro. Paradoxalmente humano, como percebera Pascal; perdido pelo paradigma constitutivo das avenidas modernas, que infletiram na esquina de Descartes, irresponsavelmente sem olhar para os lados. Tomando o trânsito em razão privada. Cedo ou tarde, essa sociedade mutante (termo de óbvio neologismo sarcástico), lançada na forma individualista e iluminista, aprenderá a solidariedade estranha ao seu paradigma. E a seus "cidadãos". Aprenderão que para brincar de Roda... todos devem dar as mãos. Ou não...

A eficácia vertical dos Direitos Fundamentais nascentes, ganha um estrangeiro e confortador sabor de positividade, para além de qualquer racionalismo de estribo quixotescamente naturalista e dependente do deformado senso comum, abolido ao sabor da Revolução Científica, do anterior período. De sua instalação. Sobre novo solo paradigmático. Com nova cidadania, método, legitimação e discurso. Novos fins e novos senhores. Constitutiva da parte material da Constituição, relegava à dita formal ou orgânica, a tricefalia cerebrina articulada na Teoria dos Freios e Contrapesos. Guardando, pois, o Leviatã nas margens do Rio Inferus, Montesquieu postou Cérberus; figura nada estrangeira ao Estado-Polícia, guardião fiel da propriedade privada de seus "cidadãos destinatários de sua existência". Talvez dissesse hoje, Sto. Agostinho: - Novos deuses, novos homens e, conseqüentemente, novas cidades.

Assim nasce o indivíduo. Nasce moderno. Com a alma vendida no pacto fáustico de um mefistofélico Leviatã, envernizado pelo racionalismo cartesiano. Se este pacto faliu na Pós-Modernidade, é porque nem os faustos de Goethe podem dar algo àquele ente perdido no seio da Sociedade do Espetáculo. No espetáculo das relações mediadas por imagens, arquétipos e simulacros. Totens do consumo, na religião do Espetáculo. Ofuscada de informação como espantalhos da cultura do não-saber. Da felicidade burra, na passividade do essencialismo revelado no transparadoxo biopolítico moderno. Mitificador da razão para fundamentar sua fé. Saltimbanco de uma novela nunca escrita. Louco... Arquetipicamente enlouquecido. Mais que louco, o "zero". O Louco.

O Positivismo é a verdadeira corporificação do espírito científico iluminista, identificando o Direito à Lei e fazendo da norma sua medida. Rule... Régua. O Juiz, sacerdote da razão legal, c'est le bouche du loi, na aspiração da 
Teoria Tripartite. A própria Hermenêutica (portanto uma Metahermenêutica, paradoxalmente negativa), ajuda a(-) fundar o Estado. Onde o Homem escraviza, a Lei liberta, discursará o liberalismo jovem. Jovens promessas. Velhas quimeras.

Com o cenário montado, inicia-se a tragédia moderna, no palco (sub)urbano do pensamento liberal burguês, com apenas quatro personagens privilegiados pelo determinista roteiro jurídico: Proprietário, marido, contratante e testador. Àquele que não postasse esses trajes, remetia-se para fora do grand monde da cidadania burguesa, encampada e biografada no Código Civil, defeso pelas muralhas do positivismo científico. Um pacto fáustico que na pós-modernidade alienaria o planeta em medidas de carbono. Um Mefisto econômico, que não tem nada mais a oferecer à humanidade, cuja crença em alguma alma também passa a ter um sabor utilitarista e mercantilista, perdida em templos improvisados na periferia social. De Lutero à Macedo. Triste imagem.

\section{Entre códigos e disciplinas; dogmas e ritos na religião do mercado}

Cego aos fantasmas axiológicos que nunca deixaram de lhe assombrar, o determinismo moderno pôs curso ao Liberalismo, messianicamente prometendo liberdade e igualdade na concretização dos valores iluministas que edificaram o individualismo que lhe é característico.

O Mercado revelaria a "Verdade", para além de quaisquer subjetividades naturais ao antigo paradigma, de feições místicas. Neutra e objetiva. Mito? A Lei da Oferta e da Procura, teria a capacidade de valorar as mercadorias em circulação, independente de qualquer mediação subjetiva? Desconstruir apresenta sua condição natural de prevalência (a)metódica, tomada a incerteza como premissa, no sutil véu da pós-modernidade, para a condição demasiadamente humana do observador enquanto intérprete. Nos bastidores da Revolução Científica derivada do Iluminismo, desenvolve-se um elemento chave para o Capitalismo impor seu darwinismo econômico, na sociedade liberal. A Revolução Industrial. Elemento indissociável a compreender-se a Sociedade de Mercado que emergirá às vésperas da Pós-Modernidade. E seus simulacros.

O artesão perde seu espaço com a chegada da Fábrica. Fenômeno que será agravado com o advento da linha de montagem. Com a Indústria, o resultado final, ao contrário do que se poderia imaginar, não é a mercadoria. Essa lógica, aparentemente inversa, explica-se nas práticas deificadas do Mercado. Com a febril demarcação e conseqüente cercamento de terras imanente ao Estado Mínimo, o êxodo rural difunde um infinito de odores novos, carregados de esperança e miséria, às ruas das principais capitais européias. Proletários. Os fiéis que chegavam em um mundo edificado em torno de um novo e sedento deus. O Mercado. 
Logo ele lhes exigiria seus sacrifícios e tributos. Um novo Leviatã... Talvez um faminto Astaroth, ou uma sensual Lilith, começava a tomar forma. O artesão acabara. Com ele, foram suas guildas e aprendizes. Sua arte e tradição. A fábrica se impõe como uma nova realidade do cenário urbano da Modernidade. Nela, o trabalhador (outrora artesão ou artista), é operário. Vende sua força de trabalho. Única mercadoria de que dispõe. Somada a liberdade de não vendela, escolhendo o valor de seu trabalho no mercado. Ou não...

O dinheiro, substituto do esquecido escambo, é o único instrumento universalizado pelo mercado, para realização das suas trocas e legitimações. É seu imperativo categórico. O indivíduo já não domina a matéria-prima do produto. Nem mesmo seu processo. Sequer é dono das ferramentas inerentes ao seu ofício no chão-de-fábrica. Nem mesmo tinha capacidade de perceber o quanto o mundo mudara ao seu redor. De muito já perdera as rédeas dessa mudança. Muitos de modo consciente.

\section{A maioria não.}

No mercado, frente às filas do "Exército do Operariado de Reserva" engrossando sem parar, o jogo da oferta e da procura tinha as cartas marcadas. E bancando o jogo, o Estado Mínimo, amorfo e imóvel em face da metástase do patrimonialismo individualista que criara em seus intestinos "neutros". O Capitalista investe. Compra ferramentas, processos e matériaprima. Ao cabo, põe seu produto no mercado, à luz da sua lógica alquímica, que o transmuta em capital, para que compre mais matéria-prima e converta em capital e... "quem cozinha o banquete?" Questionaria a sapiência de Berthold Brecht.

O jogo do capital é o jogo do Direito Civil tradicional. O direito das coisas, é caracterizado por relações entre o titular e o bem (daí denominadas reais e classificadas absolutas). O Contrato, corolário das Obrigações Civis, era fundamentalmente patrimonial. A própria obrigação somente se poderia perceber como um vínculo patrimonial entre sujeitos (no dizer de Poithier), sendo a obrigação chamada natural, revestida de inexigibilidade.

Portanto, àquele que não tivesse patrimônio, era sujeito do direito das coisas, obrigações e contratos na sua concepção tradicional? Considerando ser o sistema jurídico identificado à lei, pelo discurso positivista que alimentava o paradigma da época, a resposta é não.

Sequer ao direito de família haveria guarida ao menor estigmatizadoilegítimo, no estatuto da bastardia consolidador do aristocracismo argentário burguês, napoleônico ou vitoriano. No Direito brasileiro, somente com a Constituição de 1988, a jorge-amadeana figura da "teúda e manteúda", caracterizada na companheira ou na concubina, conseguirá adentrar uma vara de família. Sem dúvida àquele que não conseguira ser sujeito no direito das coisas, obrigações ou de família, tampouco o será no direito das sucessões tradicional. Afinal o próprio Código Civil, fossificado na trincheira de sua Teoria Geral, ousará dizer como passa o tempo e o esquecimento, em prol 
da segurança jurídica, edificando a prescrição. Fará mais. Dirá quem é pessoa! É todo àquele capaz de direitos e obrigações! Todo! Não todos!! Quem não for capaz, não será pessoa, persona, personagem, máscara. Na burlesca novela da codificação civil, de tons socialmente trágicos e politicamente pastéis. Tudo com segurança. Em nome da segurança! De quem? Para quem?

O Direito Civil tradicional, corporificado no Código enquanto "Constituição do Homem Privado"(!), perfaz com isso um estatuto de exclusão. Uma navalha econômica. Um fosso social. Não existe direito privado diante do ser. Apenas diante do ter. Na razão do mercado. Neutra... Para quem?

Construído Estado e Direito em torno dessa lógica proprietária e privatista, resta apenas aparelhá-lo com os modernos instrumentos disciplinares eficazes e coerentes ao paradigma jocosamente vitorioso. Importa remeter ao descarte social, àqueles que distanciem-se dos padrões a serem consumidos, mantidos e reproduzidos.

Assim, um homicídio tem tipo distinto para o latrocínio, em detrimento de qualquer contexto social em que se produza. Prepondera no tipo penal em análise, o elemento patrimonial em primazia ao contexto social em que se desdobre o qualificado crime. Qual o bem penal em tutela, na razão última da jurisdição criminal? A vida ou a propriedade privada?

O Código Penal concebe tipos distintos para o estupro e para o atentado violento ao pudor. Não obstante, seu fundamento é tutelar a dignidade e o direito à intimidade e opção sexual da vítima, em suas últimas fronteiras. Seria um ato pior que o outro? Poder-se-ia qualificar assim? Alguma mulher concordaria? E a extinção de punibilidade do estuprador, em ele casando com sua vítima? Qual a natureza disso? O ato de estupro perderia todo quoeficiente de brutalidade que o envolve, ressocializando o agressor ? Não se estaria em última instância tutelando o direito das sucessões, mediante o resguardo do útero como modo privilegiado de sucessão causa mortis? Direito Penal? Público ou Privado? Para quem? Certamente uma porta de entrada, à todos tidos como anormais para o homem médio do Code. Para os restos sociais. Improdutivos. "Incapitalizáveis"... Embriões econômicos, que nunca foram dados a desenvolverem-se. Destinados ao descarte(s).

\section{Dejetos do jantar à mesa do café}

Forjada a Sociedade do Mercado, o indivíduo só reconhece como espaço público o consumo, enquanto uma nova ágora da socialidade rasteira que residualmente lhe sobrou. Ele somente sente-se parte desse "novo algo" que ele é incapaz de reconhecer, quando consome. E assim se consome. Cada vez mais no e pelo Espetáculo.

O Mercado cria novas doenças e suas curas. Novos produtos para o consumo e crédito para consumi-los, enquanto produtos outros. Fundado no simulacro em sua lógica alienante de dominação, mediadora das relações cada vez mais impossibilitadas de sua natural emergência, o Mercado se 
hipertrofia. O próprio afeto, onde a doação deveria ser uma inerência, adquire a lógica da troca. Uma doação onerosa, caracterizada pelo encargo da troca. Eu dou se recebo. Isso é afeto? Não o teremos perdido em algum lugar, soterrado entre nossas próteses tecnológicas? As relações envolvidas pela lógica da troca, já nascem doentes, destinadas a serem trocadas por novas relações. O descarte é incorporado à própria lógica afetiva, economicizada e utilitarista.

O individualismo projetou um homem que é incapaz de se reconhecer no outro, por sua incapacidade de reconhecer o outro. Percebe o outro, como uma extensão de si. Que vê o mundo como ele. Não vê, portanto o outro. Vê a si mesmo, projetado no outro, incapacitando-se a reconhecer qualquer alteridade. Nessa racionalidade perversa está imersa a Sociedade Punitiva, continuada pelo biopoder inerente à Sociedade Pós-Industrial. Sem nichos para filas, agora possuidoras de um pathos social. Uma sociedade que passou a excluir digitalmente. Em tempo real. Sem analogismos! Cria um ideal da imagem, que consome o ser pelo ter, privado de consciência pela ausência de qualquer espaço de ação real, não virtual; um iter de pertencimento e entrega diante do outro... do estrangeiro... do estranho... Um iter de ação não mediada.

"Iteração". Sem coisas (res) me(i)diantes. Reiterantes... Redundantes. Existimos na busca da eficiência do consumo. Em ter muito, para em seguida querermos ter mais. E quando alcançamos... resta apenas nosso encontro conosco. Naquela rede que Neruda postara na praia... Pegando apenas a nós mesmos... nus, ao luar. Sós. Como viemos ao mundo... Como deixaremos o mundo. Encontramos o vazio de nós mesmos.

Essa frustração, característica da pós-modernidade, tem por remédio usual mais consumo. Mais vazio e frustração... e mais consumo. Reconhecemos-nos pelo que consumimos. E isso nos consome, ao consumir nossa humanidade. Reduz o espaço público ao mercado e nos (de)compõe como mercadoria. Somos fantasmas de nós mesmos! Compramos um ideal de vida para viver e descartar. Nos curvamos ao nosso próprio descarte. As inevitabilidades do Mercado, na lógica de Hayek. Externalidades, na lógica de Friedman. Pintamos uma nova Guernica. Cegos e com uma palheta rubra de sangue. No espetáculo da vida nua. Consumida. Frustante. Consome a própria humanidade, purificadora de estranhezas e anormalidades. À cada volta da Roda da Fortuna, nascem novas estranhezas e novos estrangeiros. Novos descartes a serem consumidos pela lógica do espetáculo autoinduzida. A cada volta... nova revolta. Ou não... Depende da eficiência em consumir. Ter para ser? "Des-ser"... Redundar... Ter para ter mais... Esquecendo a frustração de "não ser". Nascer... A cada morte. "Estranhificar" para legitimar a exclusão. Na lógica do descarte, não há tempo para ressocializar. Não há tempo para reinserir. Sequer há tempo para inserir ou socializar àqueles que nasceram na periferia. Fadados ao descarte. Para o Espetáculo. A humanidade cega. Prefere não ver o que se tornou... entornou. Pôs em torno... 
Nas periferias dos grandes centros. Pôs em tornos... Nos modelos em constante troca. Na segurança líquida, do método dúctil. Interessadamente líquida. Ou tomamos a pós-modernidade na recusa em sermos fantasmas de nós mesmos. Assumindo suas rédeas de incerteza, no reconhecimento da dignidade em reconhecer a busca irrealizada das liberdades prometidas. Talvez aqui repouse o sentido de dignidade concretizado em nossos valores. Atuais e atuarizados. Sem dúvida não tem raiz em Kant. Seria tão ingênuo, quanto buscar exumar seus intestinos sem considerar o idealismo alemão, na recomposição moderna do espiritualismo francês. Os homens não têm valor... Têm dignidade. As coisas têm valor.

Por si? Não era. Nós atribuíamos valor às coisas. Agora elas atribuem valor a nós. Entre nós. Enosados... Enredados. No enredo deste espetáculo sujo. De limpeza e purificação. De nosso lixo arquetípico. Codificado. Desumanizado. Nos limpamos de nós mesmos. Paramos de viver nossa humanidade para viver o Espetáculo. Parados em "nós". Paramos todos para assistir. Assistir aos nossos fantasmas nos assombrarem enquanto desfiamos a não-existência da auto-nadificação. Continuamos na imagem que fazemos que façam de nós mesmos. No Espetáculo... Esse é o único que não pode parar.

\section{Referências}

ARONNE, R. Direito Civil-Constitucional e teoria do caos-Estudos preliminares. Porto Alegre: Livraria do Advogado, 2006.

. Código Civil anotado. São Paulo: IOB/Thomson, 2005.

Síntese, 2004.

. O princípio do livre convencimento do juiz. 1. ed. Porto Alegre: Fabris, 1994.

. Titularidades e apropriação no Novo Código Civil. Breve ensaio sobre a Posse e sua

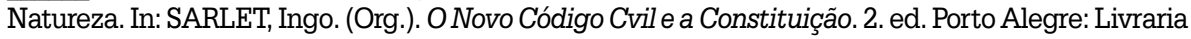
do Advogado, 2006.

Síntese, 2004.

Disposições finais. In: PEREIRA, Rodrigo da Cunha (Org.). Código Civil anotado. São Paulo:

. Propriedade e domínio. 1. ed. Rio de Janeiro: Renovar, 1998.

.Por uma nova hermenêutica dos direitos reais limitados-das raízes aos fundamentos contemporâneos.

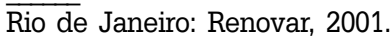

BEVILÁQUA, C. Direito das coisas. 5. ed. Rio de Janeiro: Forense, s.d. v. 1.

BAUDRILLARD. J. Tela total.. 3. ed. Porto Alegre: Sulina, 2005.

. O sistema dos objetos. 4. ed. São Paulo: Perspectiva, 2004.

BAUMAN, Z. Vidas desperdiçadas. Rio de Janeiro: JZE, 2005.

. Omal-estar da pós-modemidade. Rio de Janeiro: JZE, 1998.

. Modernidade e ambivalência. Rio de Janeiro: JZE, 1999.

. Comunidade - a busca por segurança no mundo atual. Rio de Janeiro: JZE, 2003. 
. Modernidade líquida. Rio de Janeiro: JZE, 2001.

. Globalização-as conseqüências humanas. Rio de Janeiro: JZE, 1999.

. Vida líquida. Rio de Janeiro: JZE, 2007.

BECKER, L. A.; SANTOS, E. L. Elementos para uma teoria crítica do processo. Porto Alegre: Fabris, 2002.

BECKER, L. A. (Org.) A escola de Frankfurt no Direito. Curitiba: EDIBEJ, 1999.

BOURDIEU, P. Contrafogos - Táticas para enfrentar a invasão neoliberal. Rio de Janeiro: JZE, 1998.

. Razões práticas - Sobre teoria da ação. 8. ed. Campinas: Papirus, 2007.

BOUTHOL, G. História da sociologia. São Paulo: Difel, 1976.

BURKE, P. Uma história social do conhecimento. São Paulo: JZE, 2003.

CARBONNIER, J. Flexible droit: pour une sociologie du droit sans riguer. Paris: LGDJ, 1992.

CANARIS, C. Pensamento sistemático e conceito de sistema na ciência do direito. Lisboa: Fund. Calouste Gulbenkian, 1989.

DEBORD, G. Críticaà sociedade doespetáculo.

DERRIDA, J. A farmácia de Platão. São Paulo: Iluminuras, 1991.

Gramatologia. 2. ed. São Paulo: Perspectiva, 2004.

ECO, Umberto. Tratado geral de semiótica. 4. ed. São Paulo: Perspectiva, 2002.

FACHIN, L. E. (Org.). Repensando os fundamentos do direito civil brasileiro contemporâneo. Rio de Janeiro: Renovar, 1998.

A reforma no direito brasileiro: novas notas sobre um velho debate no direito civil. Revista dos Tribunais, São Paulo: RT, n. 757, p. 64-69, 1998.

. Teoria crítica do direito civil. Rio de Janeiro: Renovar, 2000.

FOUCAULT, M. As palavras e as coisas. São Paulo: Martins Fontes, 2002. 2005.

. Arqueologia das ciências e a história dos sistemas de pensamento. 2. ed. Rio de Janeiro: Forense,

Arqueologia do saber. Rio de Janeiro: Forense, 2005.

A ordem do discurso. São Paulo: Loyola, 2006.

GILISSEN, J. Introdução histórica ao direito. 2. ed. Lisboa: Fund. Calouste Gulbenkian, 1995.

GLES, T. R. História do existencialismo e da fenomenologia. São Paulo: EDUSP, 1975. 2v.

GINESTIER, P. Pour connaître la Pensée de Camus. Paris/Montreal: Bordas, 1971.

GLEICK, J. Caos - a criação de uma nova ciência. Rio de Janeiro: Campus, 1990.

GRAVES, R. New Larousse encyclopedia of mythology. London: Hamlyn, 1978.

GONNARD, R. La propriété dansla doctrine et dans l'histoire. Paris: LGDJ, 1943.

HABERMAS, J. Técnica e ciência como “Ideologia”. Lisboa: Edições 70, 1997.

. Pensamento pós-metafísico: estudo filosófico. Rio de Janeiro: Tempo Brasileiro, 1990.

. Consciência moral e agir comunicativo. Rio de Janeiro: Tempo Brasileiro, 1989.

. Conhecimento e interesse. Rio de Janeiro: Zahar Editores, 1982.

HOBSBAWM, E. Era dos extremos: o breve século XX - 1914-1991. São Paulo: Cia. das Letras, 2003.

KUHN, T. A estrutura das revoluções científicas. 5. ed. São Paulo: Perspectiva, 1998. 
LARENZ, K. Derecho civil: parte general. 3. ed. Madri: Rev. Derecho Privado, 1978.

Metodologia da ciência do direito. 5. ed. Lisboa: Ed. Calouste Gulbenkian, 1983.

LÔBO, P. L. N. Contrato e mudança social. Revista dos Tribunais, São Paulo: RT, n. 722, p. 40-45, 1995.

. Constitucionalização do Direito Civil. Revista de Informação Legislativa, Brasília: Senado Federal,

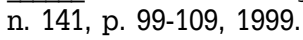

MEIRELES, J. O ser e o ter na codificação civil brasileira: do sujeito virtual à clausura patrimonial. In: FACHIN, L. Edson. Repensando os fundamentos do direito civil brasileiro contemporâneo. Rio de Janeiro: Renovar, 1998.

MONTAIGNE. A arte da conferência. São Paulo: Martins Fontes, 2004.

MORIN, E. A cabeça bem-feita: repensar a reforma, reformar o pensamento. 10. ed. Rio de Janeiro: Bertrand Brasil, 2004.

. Saberes globais e saberes locais: um olhar transdiciplinar. Rio de Janeiro: Garamond, c2001. . Introdução ao pensamento complexo. Lisboa: Inst.Piaget, 1991.

NIETZSCHE, F. W. Assim falou Zaratustra. São Paulo: Martin Claret, 2003.

. Ecce homo: como cheguei a ser o que sou. São Paulo: Martin Claret, c2001.

. A Gaia ciência. São Paulo: Companhia das Letras, c2001.

. O Anticristo. 5. ed. Rio de Janeiro: INCM, 1978.

SARTRE, Jean-Paul. A idade da razão. São Paulo: DIFEL, 1976.

PASCAL, B. Pensamentos. São Paulo: Martin Claret, 2004.

. A arte de persuadir. São Paulo: Martins Fontes, 2004.

PASQUALINI, A. Hermenêutica e sistema jurídico. Porto Alegre: Livraria do Advogado, 1999.

. O público e o privado. In: SARLET, Ingo (Org.). O direito público em tempos de crise. Porto Alegre: Livraria do Advogado, 1999.

PEIRCE, C. Semiótica. 3. ed. São Paulo: Perspectiva, 2003.

PERLINGIERI, P. Perfis do direito civil: introdução ao direito civil constitucional. Rio de Janeiro: Renovar, 1997.

PRIGOGINE, I. O fim das certezas: tempo, caos e as leis da natureza. São Paulo: UNESP, 1996.

PRIGOGINE, I.; STENGERS, I. La novelle alliance. Paris: Gallimard, 1979.

POINCARÉ, H. A ciência e a hipótese. Brasília: UNB, 1988.

RUSSELL, B. História do pensamento ocidental: a aventura das idéias dos pré-socráticos a Wittgenstein. Rio de Janeiro: Ediouro, 2001.

SANTOS, B. de S. Um discurso sobre as ciências. São Paulo: Cortez, 2005.

. Conhecimento prudente para uma vida decente: um discurso sobre as ciências revisitado. São Paulo: Cortez, 2004.

. Pela mão de Alice: o social e o político na pós-modernidade. 8. ed. São Paulo: Cortez, 2001. . O discurso e o poder: ensaio sobre a sociologia da retórica jurídica. Porto Alegre: Fabris, 1988.

SARLET, I. W. A eficácia dos direitos fundamentais. Porto Alegre: Livraria do Advogado, 2004. (Org.). O Direito Público em tempos de crise. Porto Alegre: Livraria do Advogado, 1999. 
SARLET, I. W. (Org.). O Novo Código Civil e a Constituição. 2. ed. Porto Alegre: Livraria do Advogado, 2006.

(Org.). A Constituição concretizada: construindo pontes com o público e o privado. Porto Alegre: Livraria do Advogado, 2000.

STEWART, I. Será que Deus joga dados? A nova matemática do caos. Rio de Janeiro: JZE, 1991.

SCHWARTZ, G. A Constituição, a Literatura e o Direito. Porto Alegre: Livraria do Advogado, 2006.

TEPEDINO, G. Temas de Direito Civil. 3. ed. Rio de Janeiro: Renovar, 2004. v. 1.

. Temas de Direito Civil. 2. ed. Rio de Janeiro: Renovar, 2006. v. 2.

. (Org.). Problemas de Direito Civil-Constitucional. Rio de Janeiro: Renovar, 2001. 